Article

\title{
Synthesis, Characterization and Mechanical Properties of Novel Bio-Based Polyurethane Foams Using Cellulose-Derived Polyol for Chain Extension and Cellulose Citrate as a Thickener Additive
}

\author{
Loredana Maiuolo ${ }^{1, *}$, Fabrizio Olivito ${ }^{1, *} \mathbb{C}$, Vincenzo Algieri ${ }^{1}\left(\mathbb{D}\right.$, Paola Costanzo ${ }^{1}\left(\mathbb{D}\right.$, Antonio Jiritano ${ }^{1}(\mathbb{D}$, \\ Matteo Antonio Tallarida ${ }^{1} \mathbb{D}$, Antonio Tursi ${ }^{1}$, Corradino Sposato ${ }^{2}$, Andrea Feo ${ }^{2} \mathbb{D}$ and Antonio De Nino ${ }^{1, *(D)}$ \\ 1 Department of Chemistry and Chemical Technologies, University of Calabria, 87036 Rende, CS, Italy; \\ vincenzo.algieri@unical.it (V.A.); paola.costanzo@unical.it (P.C.); antonio.jiritano@unical.it (A.J.); \\ matteoa.tallarida@unical.it (M.A.T.); antonio.tursi@unical.it (A.T.) \\ 2 ENEA, Italian National Agency for New Technologies, Energy and Sustainable Economic Development, \\ Trisaia Research Centre, S.S. 106 Ionica, km 419 + 500, 75026 Rotondella, MT, Italy; \\ corradino.sposato@enea.it (C.S.); andrea.feo@enea.it (A.F.) \\ * Correspondence: maiuolo@unical.it (L.M.); fabrizio.olivito@unical.it (F.O.); denino@unical.it (A.D.N.)
}

Citation: Maiuolo, L.; Olivito, F.;

Algieri, V.; Costanzo, P.; Jiritano, A.; Tallarida, M.A.; Tursi, A.; Sposato, C.; Feo, A.; De Nino, A. Synthesis, Characterization and Mechanical Properties of Novel Bio-Based Polyurethane Foams Using Cellulose-Derived Polyol for Chain Extension and Cellulose Citrate as a Thickener Additive. Polymers 2021, 13, 2802. https://doi.org/10.3390/ polym13162802

Academic Editors: Arn Mignon and Miguel Angel Rodríguez-Pérez

Received: 22 July 2021

Accepted: 16 August 2021

Published: 20 August 2021

Publisher's Note: MDPI stays neutral with regard to jurisdictional claims in published maps and institutional affiliations.

Copyright: (c) 2021 by the authors Licensee MDPI, Basel, Switzerland. This article is an open access article distributed under the terms and conditions of the Creative Commons Attribution (CC BY) license (https:// creativecommons.org/licenses/by/ $4.0 /)$

\begin{abstract}
A novel series of bio-based polyurethane composite foams was prepared, employing a cellulose-derived polyol for chain extension and cellulose-citrate as a thickener additive. The utilized polyol was obtained from the reduction reaction of cellulose-derived bio-oil through the use of sodium borohydride and iodine. Primarily, we produced both rigid and flexible polyurethane foams through chain extension of the prepolymers. Secondly, we investigated the role of cellulose citrate as a polyurethane additive to improve the mechanical properties of the realized composite materials. The products were characterized by FT-IR spectroscopy and their morphologies were analysed by SEM. Mechanical tests were evaluated to open new perspectives towards different applications.
\end{abstract}

Keywords: bio-based polyurethanes; prepolymers; cellulose-derived polyol; cellulose-citrate; polyurethane composites

\section{Introduction}

During the last decade, industrial and academic interest in the conversion of renewable biomass into fuels, chemicals and useful materials grew enormously [1,2]. In contrast to the limited fossil sources, agricultural wastes represent an opportunity because they are widely available, with their annually produced quantity estimated at around $2 \times 10^{11}$ tons per year [3,4]. In terms of the future prospect of a totally sustainable economy, chemistry plays a central role [5-7]. Cellulose is the major component of natural feedstocks and the most important efforts of the scientific community are focused on the development of new methodologies for its transformation [8-11]. Pyrolysis is one of the oldest chemical methods to convert cellulose into useful platform molecules such as sugars, furans or bio-oil mixtures [12-14]. The harsh conditions related to high temperature and pressure were substituted, over the years, by milder approaches [15-18]. However, under milder pressure and temperature, hydrolysis is usually accompanied by the use of such mineral acids as sulfuric or hydrochloric acid, and this involves damage to process equipment as well as negative environmental impact $[19,20]$. Unconventional solvents such as ionic liquids or deep eutectic solvents solved many environmental and procedural problems [21,22], but they are still limited by the difficulty of recovering the products, due to their high affinity for these phases [23-26]. In this ambit, novel surfactant-based ionic liquids are receiving attention due to their ease of preparation, low cost, and inherent added-value properties; in fact, their (tuneable) amphiphilic nature can, in principle, help in solving affinity problems, 
but applications are still far from being achieved $[27,28]$. Ball milling and ultrasounds are the most used physical methods for the pre-treatment and the conversion of cellulosic biomass, but the scalability of these methods is usually limited $[29,30]$. Cellulose-derived products are extremely versatile building blocks for the production of materials for engineering applications, medical equipment, food-related purposes, biofuels and many other applications [31-33]. Polyurethanes (PUs) are multifunctional polymers that have been known and produced for a long time, with wide commercial diffusion due to their low cost and significant versatility, having been used, for example, as thermal insulation materials $[34,35]$. Conventional PUs can be formed by a very exothermic reaction of isocyanates and polyols [36] but, in recent years, industrial and research efforts have been focused on the production of bio-based products with more eco-sustainable methodologies [37-40].

Cellulose can be turned into valuable polyols that can be used as a starting materials or chain extenders for polyurethane synthesis [41-43]. We recently developed a simple and fast method for the contemporary conversion of microcrystalline cellulose into a furanenriched bio-oil and cellulose citrate [44]. In another recent work, we proved the efficacy of some inorganic salts, such as sodium chloride, in the reaction of PEG 400 and different aliphatic diisocyanates for the production of polyurethanes [45].

The principal goal of this work was the development of a novel, efficient and sustainable approach for the synthesis of polyurethane foams and polyurethane composites using two renewable materials and a green catalyst. More specifically, the furan-enriched bio-oil obtained through our previous procedure [44] was successfully reduced using a simple open flask reaction into a polyol mixture, composed mainly of 2,5-bis(hydroxyl methyl)furan. More precisely, this furan diol was proven, over the years, to have different applications, and the synthetic efforts towards its facile production are growing rapidly [46-48]. For the aforementioned reasons, we used-for the first time, to our knowledge- this cellulose-derived polyol, which was synthesized through our simple and eco-compatible procedure, as a chain extender to synthesize novel bio-based polyurethane foams. Subsequently, the addition of the second renewable product into the same reaction mixture, with cellulose citrate as an additive, allowed us to realize novel polyurethane composite foams with enhanced mechanical properties. The final materials were chemically characterized by FT-IR spectroscopy and their morphologies were analysed by SEM. Their mechanical properties were preliminary evaluated to facilitate new application-based studies using these materials. Finally, a conceptualization regarding the chemical interactions of cellulose citrate inside the urethane chains was carried out.

\section{Materials and Methods}

Tetrahydrofuran (THF) was purchased from Carlo Erba (Milan, Italy) at analytical grade, and freshly distilled before use after drying over sodium sulfate. Acetone was purchased from Honeywell at a high purity grade and used without further purification. Microsrystalline cellulose type 102 was purchased from Roquette (Lestrem, France) at high purity. Citric acid was purchased from Sigma Aldrich (St. Louis, MO, USA) at 99\% purity grade. Sodium borohydride was purchased from Carlo Erba (Milan, Italy) at 95\% purity grade. Iodine was purchased from Carlo Erba (Milan, Itay) at the analytical grade. Polyethylene glycol (PEG) 400 was purchased from Thermo Fisher Scientific (Waltham, MA, USA) at 99\% purity grade. Isophorone diisocyanate (IPDI) 3, 4,4'-methylenedicyclohexyl diisocyanate ( $\left.\mathrm{H}_{12} \mathrm{MDI}\right)$ 4, and 2,2,4-trimethyl hexamethylene diisocyanate (TMDI) 5 were purchased from EVONIK INDUSTRIES (Essen, Germany), at 95\% purity grade. Sodium chloride and sodium sulfate anhydrous was purchased from Sigma Aldrich (St. Louis, MO, USA) at analytical grade. IR spectra of all products are reported in the Supplementary Material (Sections S2, S3 and S5).

\subsection{Bio-Oil Reduction into Polyol 1}

A quantity of $50 \mathrm{~g}$ of bio-oil was dissolved in $200 \mathrm{~mL}$ of THF dry in a $500 \mathrm{~mL}$ one-neck round bottom flask. In addition, $12.5 \mathrm{~g}$ ( $25 \%$ in weight respect to bio-oil) of $\mathrm{NaBH}_{4}$ was 
added portion-wise and hydrogen was released from the reaction flask. After one hour, $15 \mathrm{~g} \mathrm{(30 \%} \mathrm{in} \mathrm{weight} \mathrm{respect} \mathrm{to} \mathrm{bio-oil)} \mathrm{of} \mathrm{iodine} \mathrm{was} \mathrm{added} \mathrm{slowly} \mathrm{while} \mathrm{the} \mathrm{hydrogen}$ was released from the reaction flask. After one hour, the excess $\mathrm{NaBH}_{4}$ was quenched with aqueous $\mathrm{HCl} 1 \mathrm{M}$. The mixture was filtered through a sintered glass funnel. The solution was dried over sodium sulphate, filtered, and the solvent was removed under vacuum to obtain a polyol in the form of a brown oil, with a yield of $85-90 \%$. The LCMS and FT-IR spectra of bio-oil and polyol are reported in the Supplementary Material (Sections S4 and S5).

\subsection{Hydroxyl Group Content of Biomass Derived Polyol 1}

Polyol 1 was initially esterified using phthalic anhydride according to an earlier study [49]. In the same reaction flask, phthalic anhydride (112 g, 0.76 mols) and imidazole $(17 \mathrm{~g}, 0.25 \mathrm{mols})$ were dissolved in pyridine $(700 \mathrm{~mL})$ (this mixture is called phthalation reagent). One gram of polyol and $25 \mathrm{~mL}$ of the phthalation reagent were mixed under stirring at $100{ }^{\circ} \mathrm{C}$ for $15 \mathrm{~min}$. The mixture was cooled down to room temperature and $50 \mathrm{~mL}$ of pyridine and $10 \mathrm{~mL}$ of distilled water were added. The tritant solution $\mathrm{NaOH}$ $(0.5 \mathrm{M})$ was added until the pink ending point $(1 \mathrm{~mL}$ of phenol-phthalein solution, $1 \% \mathrm{w} / \mathrm{v}$ in $\mathrm{EtOH}$, was used as indicator). The experiments were replicated three times and the value expressed as a mean value. The hydroxyl group content was determined using the following equation:

$$
\text { Hydroxyl number }=\frac{(B-S)(56.1)(N)}{W}
$$

$B=$ the volume of the blank $(\mathrm{mL})$ at the ending point; $S=$ the volume of the substrate $(\mathrm{mL})$ at the ending point; $N=$ the normality of the $\mathrm{NaOH}$ solution; $W=$ the weight of the substrate. The $\mathrm{OH}$ content of cellulose-derived polyol 1 was $310 \mathrm{mg} \mathrm{KOH} / \mathrm{g}$.

\subsection{Prepolymer Synthesis $\mathbf{6}-\mathbf{8}$}

The detailed procedure is reported in the literature [45]. Briefly, three different prepolymers 6-8 were synthesized using the relative diisocyanates $3-\mathbf{5}$ at a molar excess of 2.5:1 with respect to PEG 4002 . Water was used as a blowing agent at a weight percentage of $5.6 \%$ with respect to PEG 4002 . The reagents were added in the following order in a plastic container: PEG 400 2, distilled water and $\mathrm{NaCl}$ as catalyst. The mixture was stirred using a mechanical apparatus. The appropriate diisocyanate was added and the mixture was vigorously stirred. The blend was warmed up to $70{ }^{\circ} \mathrm{C}$ for one hour until diisocyanate consumption. The three prepolymers $6-\mathbf{8}$ were obtained using the same procedure in the form of a colourless gel. The reaction was monitored by FT-IR spectroscopy with respect to the isocyanate signal. The produced prepolymers were defined as stable in accordance with the standard titration method, ASTM D 2572-97, using di- $n$-butylamine [49].

\subsection{Synthesis of PU Foams $\mathbf{9 - 1 1}$ Using Polyol 1 as a Chain Extender}

Polyol 1 at 30\% weight with respect to the prepolymer was added to the freshly prepared prepolymer, and the mixture was vigorously and mechanically stirred for a few minutes in the same plastic container. After that, the same mixture was reversed in a steel mold (Supplementary Material, Section S6) and the system was closed under pressure at room temperature. After eight hours, the polyurethane foam was obtained in the final form for further use (see Supplementary Material, Section S7). The disappearance of the isocyanate signal was monitored by FT-IR spectroscopy.

\subsection{Preparation of PU Composite Foams 12-14 Using Cellulose Citrate as a Thickener Additive}

Polyol 1 at $30 \%$ weight and cellulose citrate at $20 \%$ weight, with respect to the prepolymer, were added sequentially in the same plastic container as the prepolymer, and the mixture was vigorously and mechanically stirred for a few minutes. After that, the same mixture was reversed in a steel mold and the system was closed under pressure at room temperature. After eight hours, the polyurethane foam was obtained in the final 
form for further use. The disappearance of the isocyanate signal was monitored by FT-IR spectroscopy.

\subsection{Fourier-Transform Infrared Spectroscopy (FT-IR)}

FT-IR spectra were acquired using the Shimadzu IRAffinity-1S spectrometer (Shimadzu Corporation, Kyoto, Japan) in the spectral region of 400 to $4000 \mathrm{~cm}^{-1}$ with a resolution of $1 \mathrm{~cm}^{-1}$, with 48 scans undertaken for a single analysis, and the $\mathrm{KBr}$ pellets technique used. The $\mathrm{KBr}$ pellets were obtained by mixing the substrate with $\mathrm{KBr}$ powder (ratio 1:100) and by pressing with a hydraulic press. All spectra are collected in the Supplementary Material (Sections S2, S3 and S5).

\subsection{Scanning Electron Microscopy (SEM)}

Morphological studies of PU composites were carried out using a LEO 420 scanning electron microscope (SEM, Zeiss, Oberkochen, Germany), operating with vacuum conditions of $9 \times 10^{6}$ Torr at an accelerating voltage of $15 \mathrm{kV}$. Before analysis, all substrates were gold metallized using an Auto Sputter Coater (Agar, Stansted, UK). Images were taken with 100 SEM micrograph magnications. The cell structure analysis was conducted using the Aphelion ${ }^{\mathrm{TM}}$ software version 4.5.0. The program, through the use of SEM images, provided the cell surface and cell number. Furthermore, the anisotropy index was calculated as the ratio of cell height to width in the perpendicular direction of the foam growth.

\subsection{Mechanical Test}

Mechanical tests were performed in accordance with UNI EN ISO 3386-2:2010, “Flexible cellular polymeric materials, Determination of stress-strain characteristic in compression. Part 2: High density material". The test pieces were cubes with square load-bearing surfaces of $40 \mathrm{~mm}$ minimum size.

An Instron 3369 double column universal machine with a load cell of $50 \mathrm{kN}$, equipped with two circular plates of $160 \mathrm{~mm}$ in diameter, was used for the test. The compression plate moved at a uniform low rate of $2 \mathrm{~mm} / \mathrm{min}$.

\section{Results and Discussion}

The conversion of microcrystalline cellulose (MCC) into multi-functional molecules is intricate because of its high ordered crystalline structure and the low accessibility, which limit the interactions with chemicals and the consequent depolymerisation [50,51]. In our previous work, we proved the role of molten citric acid in the contemporary hydrolysis and esterification of MCC [44]. With the aim of producing a renewable polyol, the obtained furan-enriched bio-oil was reduced by a procedure employed for the conversion of carboxylic acids, which makes use of sodium borohydride and iodine, as mild reducing agents, in an open-air system [52]. This reaction is useful for bio-oil reduction because aldehydes and ketones can be reduced by sodium borohydride while the sodium borohydride/iodine system is necessary for the reduction of carboxylic groups. The reaction is shown in Scheme 1.

The newly synthesized polyol 1 was obtained as a dark highly viscous oil following two hours of the aforementioned one-pot reaction, and 2,5-bis(hydroxymethyl)furan was identified as the main compound through the LC-MS technique (see Supplementary Material for FT-IR and LC-MS spectra of polyo 1, Sections S3 and S4).

It is a common practice for the production of polyurethane foams to use a twostep methodology through which the prepolymers produced in the first step can be extended with short diols in the second step [53]. Initially, we followed our previously reported method for the synthesis of prepolymers using polyethylene glycol (PEG 400) (2) with three different aliphatic diisocyanates-isophorone diisocyanate (IPDI) (3), 4,4' methylenedicyclohexyl diisocyanate $\left(\mathrm{H}_{12} \mathrm{MDI}\right)(4)$ and 2,2,4-trimethyl hexamethylene diisocyanate (TMDI) (5)—and sodium chloride as the catalyst [45]. We chose these diisocyanates as source of polyurethanes not only because of their easy commercial availability, but 
also due to their aliphatic nature. In fact, the aromatic diisocyanates are certainly more commonly used, but they are very toxic. Moreover, few works in the literature that involve the use of aliphatic diisocyanates are reported [54,55], and this fact prompted us to develop an adequate and more eco-friendly synthetic strategy.<smiles>OCc1ccc(CO)o1</smiles><smiles>O=C(O)c1ccc(C(=O)O)o1</smiles><smiles>O=Cc1ccc(CO)o1</smiles><smiles>O=Cc1ccc(C(=O)O)o1</smiles>

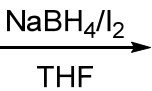

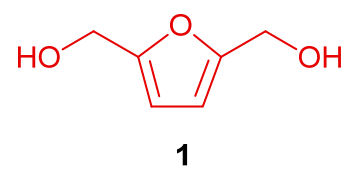

Cellulose-derived polyol

Scheme 1. Bio-oil reduction to cellulose-derived polyol.

The reaction products (6-8) are shown in Scheme 2.

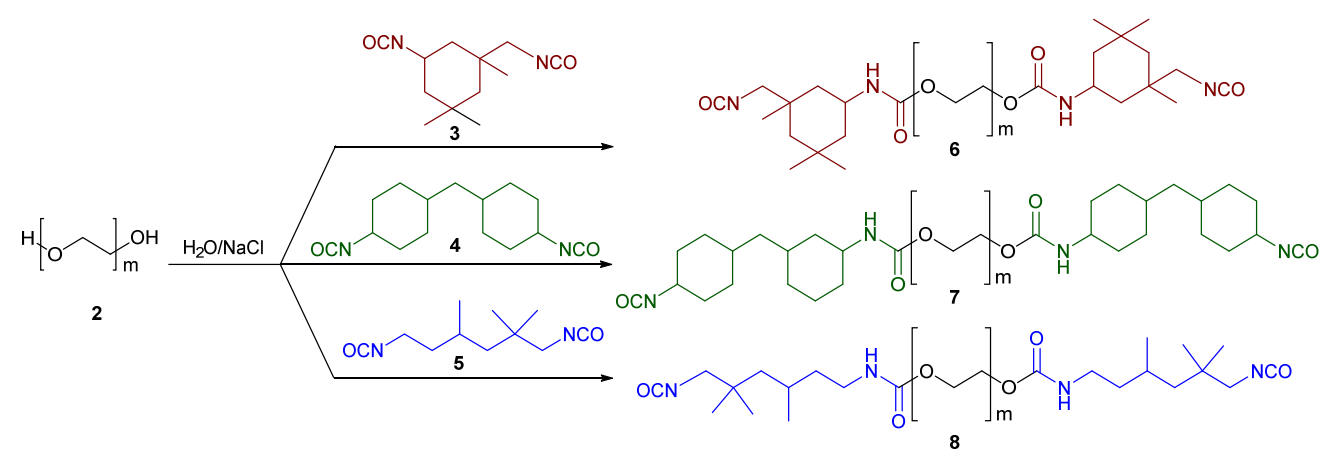

Scheme 2. Reaction scheme for the synthesis of the prepolymers (6-8).

Successively, we employed the cellulose-derived polyol (1) as a chain extender for the three prepolymers (6-8) (Scheme 3). The reaction was conducted, without the addition of any ulterior catalyst, in a closed steel mold, at room temperature, and the products (9-11) were obtained in the form of polyurethane foams after $8 \mathrm{~h}$. The quantitative conversion was verified by FT-IR analysis through the complete disappearance of the isocyanate signal (see Supplementary Material, Section S5).

The properties of the realized composite materials were chemically characterized by FT-IR spectroscopy (Figure 1). We marked the characteristic peaks of the polyurethane structure. The vibrational bands near $3330 \mathrm{~cm}^{-1}$ are relative to $\mathrm{N}-\mathrm{H}$ stretching vibrations. The shoulder at its high-frequency side (around $3600 \mathrm{~cm}^{-1}$ ) can be due to tightly bounded or monomeric residual molecules of water [56]. The IR signal in the region near $3000 \mathrm{~cm}^{-1}$ corresponds to both the asymmetrical and symmetrical stretching vibrations of aliphatic $\mathrm{C}-\mathrm{H}$. The signal near $1700 \mathrm{~cm}^{-1}$ corresponds to $\mathrm{C}=\mathrm{O}$ stretching vibration. The band above $1500 \mathrm{~cm}^{-1}$ is probably relative to $\mathrm{N}-\mathrm{H}$ bending vibrations and C-N stretching vibrations. The IR signal near $1100 \mathrm{~cm}^{-1}$ is relative to O-C-O stretching frequency. The band in the region near $950 \mathrm{~cm}^{-1}$ is relative to the $=\mathrm{C}-\mathrm{H}$ bending vibrations of furan $[57,58]$.

Finally, cellulose citrate was employed in the same polyurethane formulations as an additive and the relative polyurethane composites were obtained (12-14) (Table 1, Section S8).

For example, Figure 2 shows the interaction forces between cellulose citrate and the chains of polyurethane 14. Considering the chemical nature of polyurethane chains and cellulose citrate, we suppose a strong interaction between them, assisted by a hydrogen bond network. 

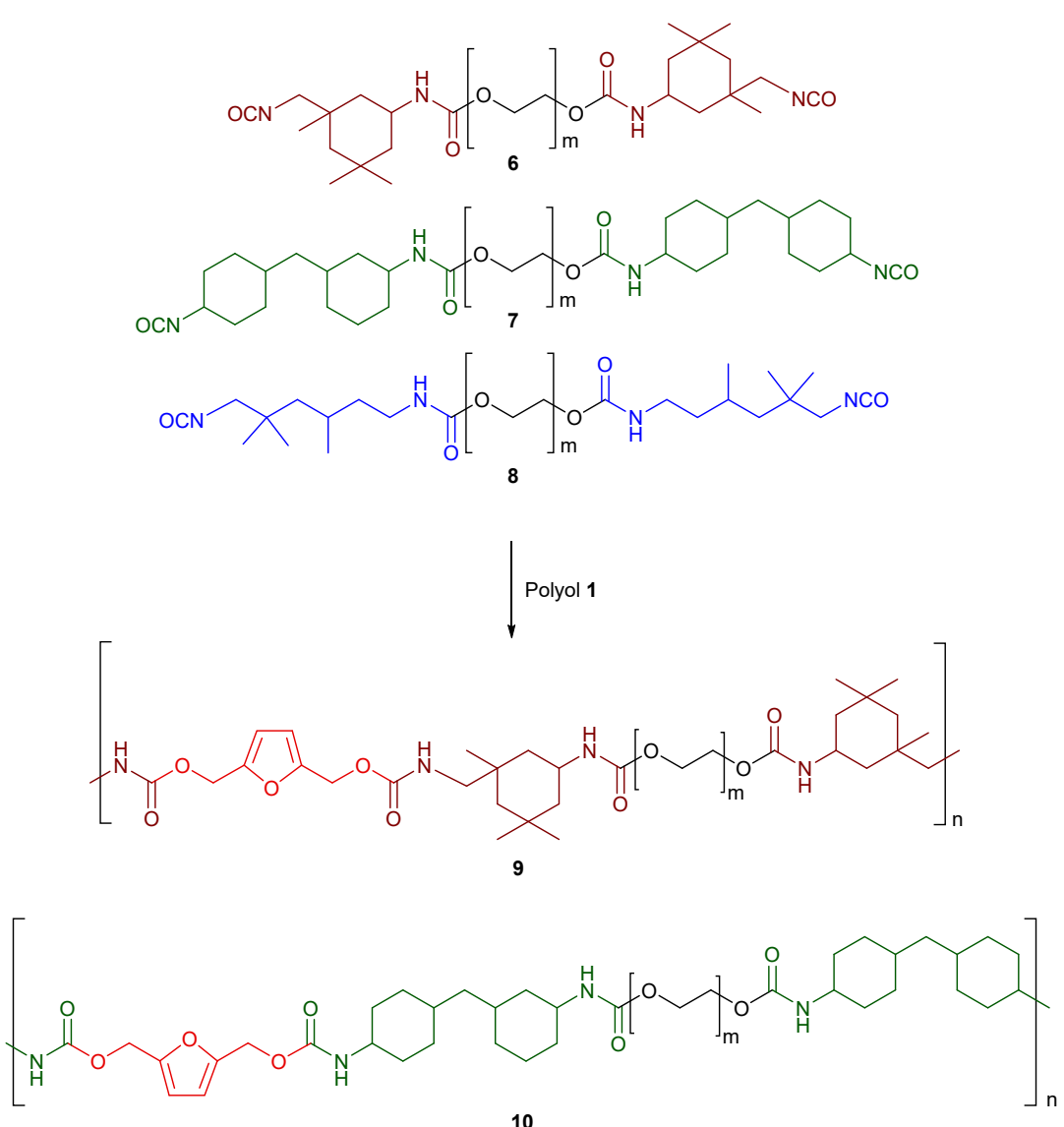<smiles>CCC(C)CC(C)(C)CC(C)CCNC(=O)OCCOC(=O)NCCCC(C)(C)CC(C)(C)CNC(=O)OCc1ccc(COC(=O)N(C)CC)o1</smiles>

Scheme 3. The final products after chain extension with polyol 1.

The presence of the hydrogen bonds could be confirmed by FT-IR spectra, as can be observed in the spectrum of materials 12-14. In fact, the band in the range of $3600-2800 \mathrm{~cm}^{-1}$ is very broad and can also encompass the vibration signal of the -OH group (Figure 3).

Moreover, in the literature, a shift to lower frequencies was documented in the carbonyl group when this group took part in hydrogen bonds [59]. The shift was evident for the $\mathrm{C}=\mathrm{O}$ stretching of the citrate group, which, from its typical vibration signal near $1735 \mathrm{~cm}^{-1}$ in cellulose citrate, was evidently shifted to lower frequency of $1700 \mathrm{~cm}^{-1}$ in all of the composites due to the fact that this molecule was engaged in a network of hydrogen bonds.

Scanning electron microscopy observations were carried out to monitor the structure of PUs 9-11 and PU composites 12-14 (Figure 4). In all cases, the morphological analysis shows the typical polyurethane structure. In the case of $\mathbf{9}$ (Figure 4a) and $\mathbf{1 2}$ (Figure $4 b$ ), two types of pores can be observed, large and small, with dimensions of 500 and $150 \mu \mathrm{m}$, respectively. Both types of pores are evenly distributed in the matrix. For $\mathbf{1 0}$ (Figure 4c) and 13 (Figure 4d), the structure appears compact and devoid of pores; in particular, for $\mathbf{1 3}$ (Figure $4 \mathrm{~d}$ ), a roughness, attributable to the presence of cellulose citrate, is observed on its surface. For $\mathbf{1 1}$ (Figure 4e) and $\mathbf{1 4}$ (Figure 4f), both still have a pore-rich structure with sizes between 250 and $50 \mu \mathrm{m}$, but 14 appears more compact than 11 [60]. Ultimately, the morphological analysis indicates that the presence of cellulose citrate generates a decrease in the size of the pores and/or a greater compactness, with a consequent increase in density, as also found in the mechanical characterizations. These findings could be attributable 
to the interaction forces between the cellulose citrate and the polyurethane chains. Apart from their mutual chemical affinity, this hypothesis could be reinforced by the results of some studies which pointed out that, in cases of blending of differently sized molecules, a spontaneous structuring takes place, driven by the fact that smaller molecules tend to be more likely to occupy the voids made by bigger ones, with a compression of volume and, overall, a more compact structure [61,62].

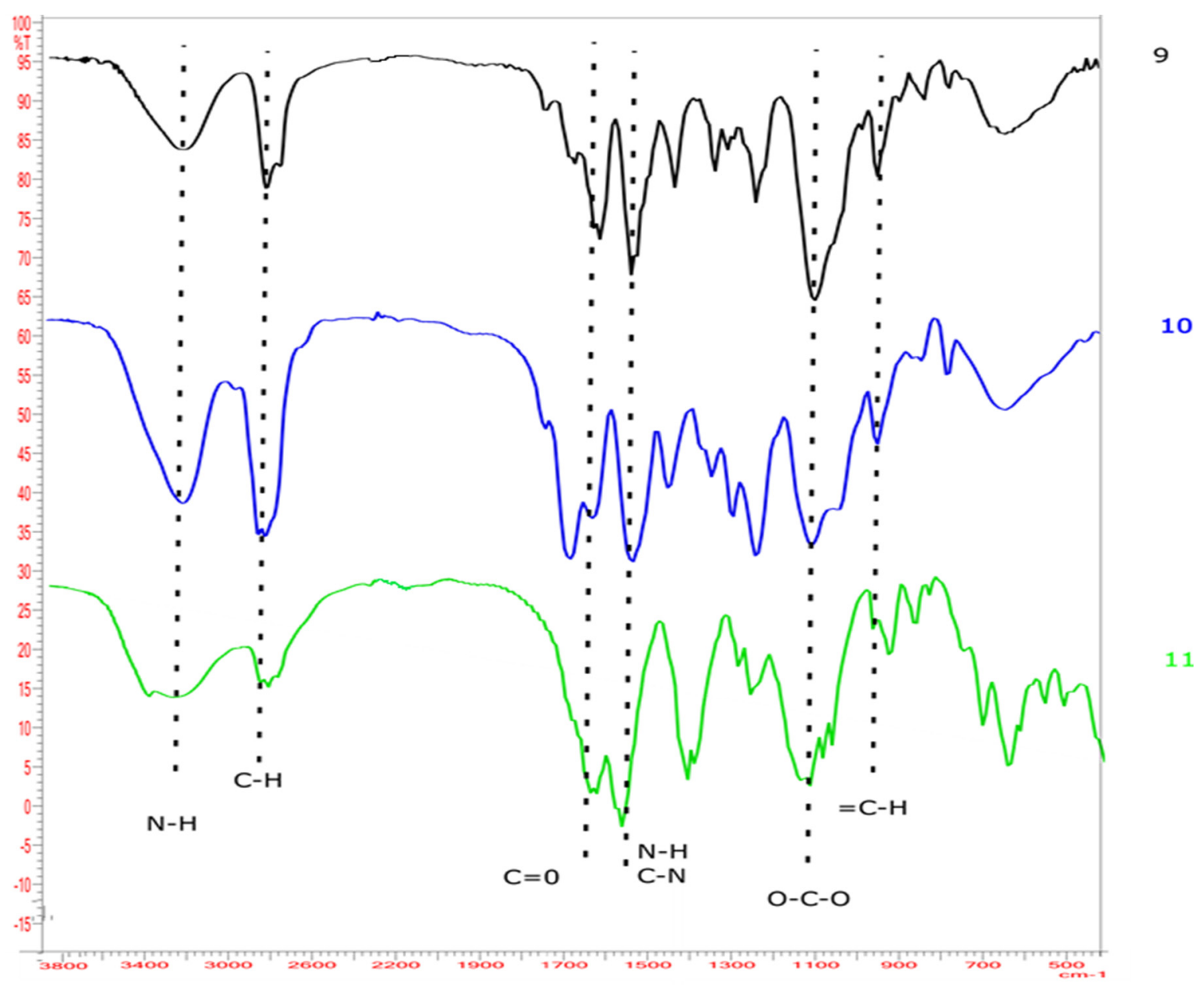

Figure 1. FT-IR spectra of the products (9-11).

Table 1. Polyurethane composite materials 12-14.

\begin{tabular}{cccc}
\hline PU & Chain Extender & Additive & PU Composite \\
\hline $\mathbf{9}$ & Polyol 1 & Cellulose citrate & $\mathbf{1 2}$ \\
$\mathbf{1 0}$ & Polyol 1 & Cellulose citrate & $\mathbf{1 3}$ \\
$\mathbf{1 1}$ & Polyol 1 & Cellulose citrate & $\mathbf{1 4}$ \\
\hline
\end{tabular}

Structural parameters were determined, and are included in Table 2.

The anisotropy index is defined as the ratio of the length to the width of the cell. When this ratio is close to 1 , the shape of the cell approaches a sphere [63]. The cells of $\mathbf{9 , 1 1}, \mathbf{1 2}$ and $\mathbf{1 4}$ in the cross section, which were perpendicular to the direction of the foam growth, were characterized by anisotropy index very close to 1 . These values indicate that the cells have almost spherical shapes. Therefore, the introduction of cellulose citrate into the systems does not change the shape of the cells, considering that the values of the anisotropy index are similar in all systems. It was observed that, due to the nucleation effect, the addition of cellulose citrate for PU composites $\mathbf{1 2}$ and $\mathbf{1 4}$ increased the number of cells in the cross section of the foam, as compared to the corresponding additive-free PU systems 
9 and 11, respectively. The effect of increasing the number of cells after adding cellulose citrate or other fillers was reported in the literature [64,65]. For $\mathbf{1 0}$ and 13, the evaluation of the characteristics of the cellular structures was not performed as they appeared compact and devoid of pores, as can be seen in Figure $4 \mathrm{c}, \mathrm{d}$.<smiles>CC(C)CC(C)(C)CC(C)C</smiles>

Figure 2. Graphical representation of the composite material 14 derived from cellulose citrate and polyurethane 11.

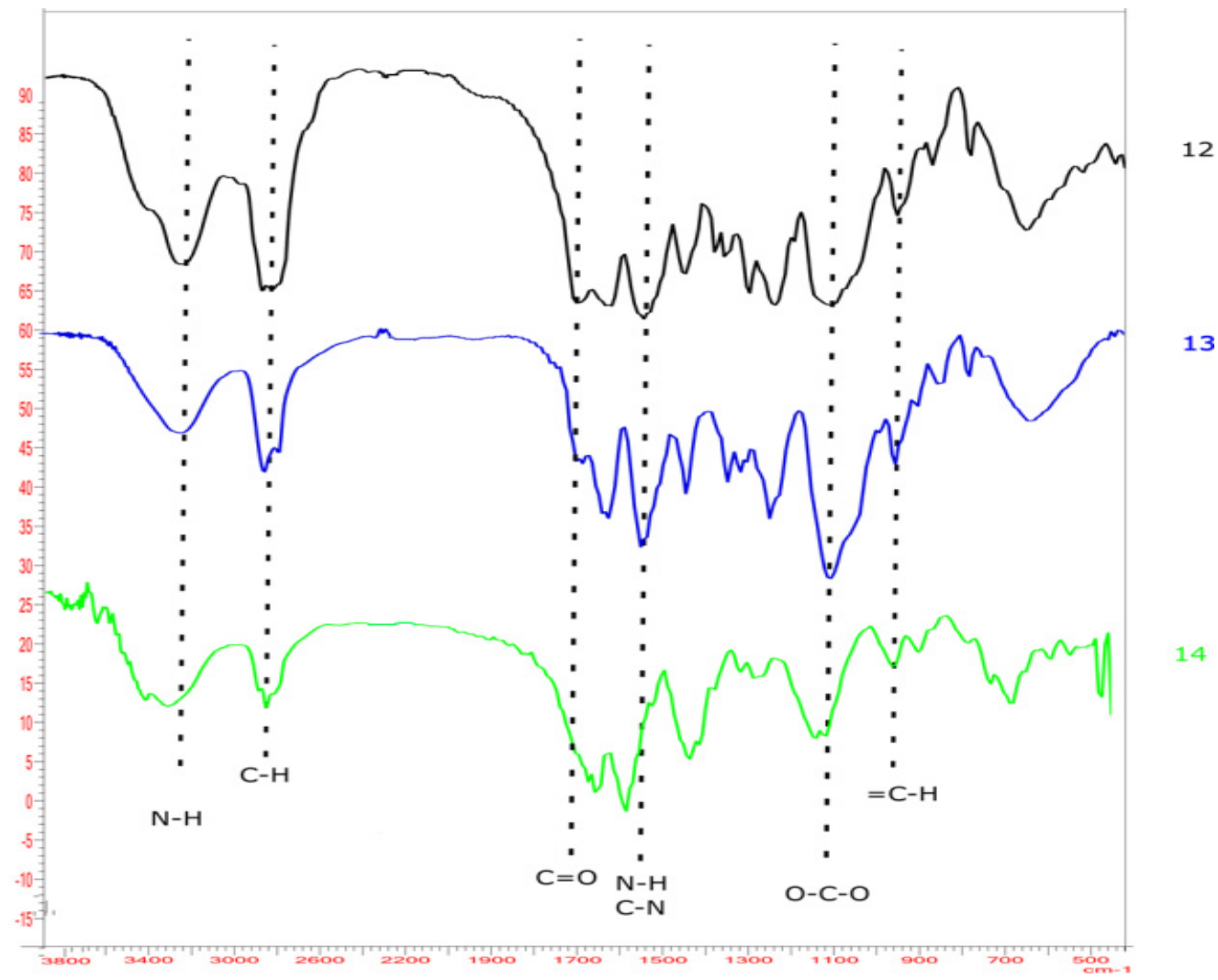

Figure 3. FT-IR spectrum of $\mathbf{1 4}$ that can confirm the presence of hydrogen bonds. 

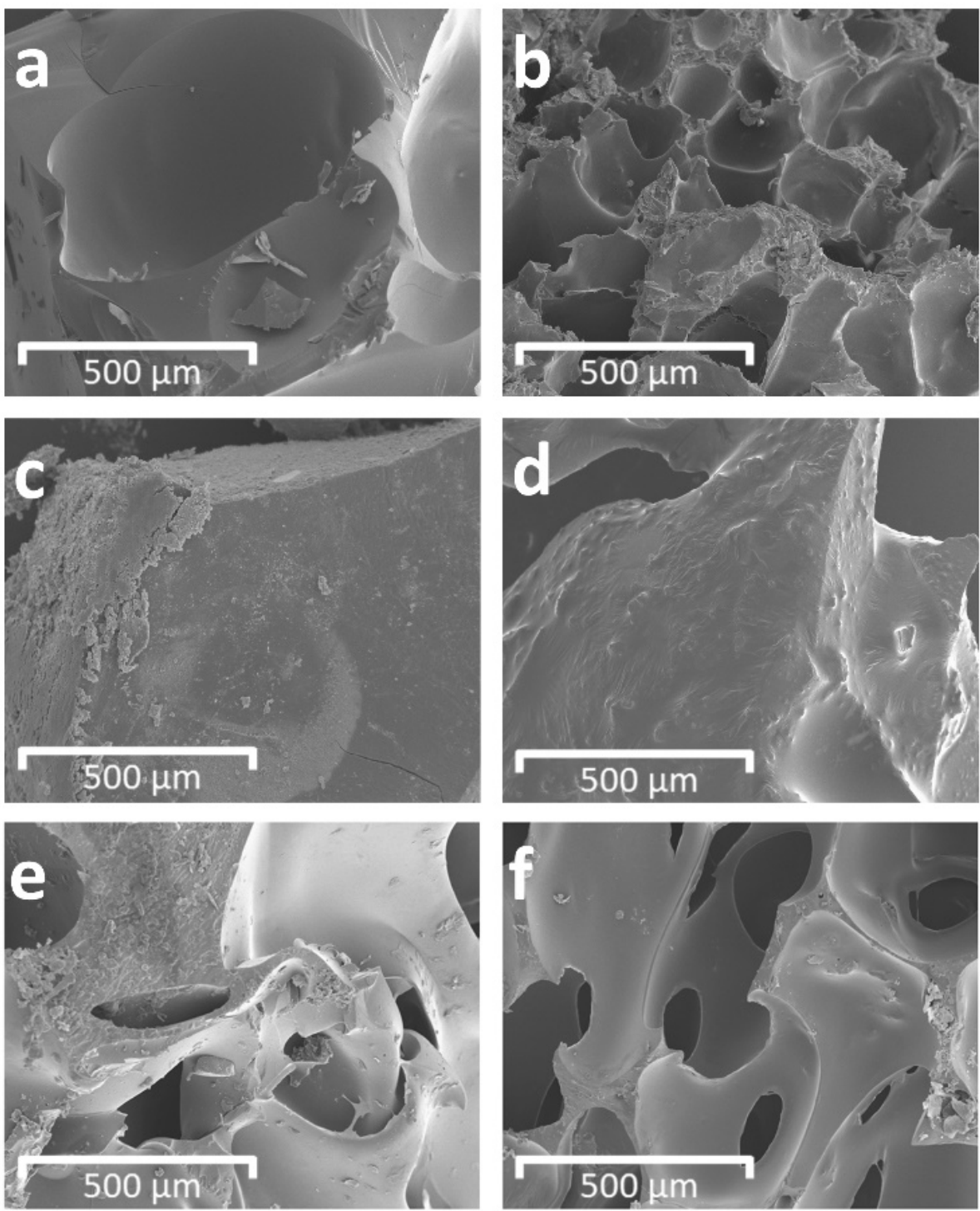

Figure 4. Scanning electron microscopy (SEM) images of structure of PUs and PU composites ( $\times 100$ magnification): (a) 9, (b) 12, (c) 10, (d) 13, (e) 11, (f) 14.

Table 2. Characteristics of PU cellular structure.

\begin{tabular}{|c|c|c|c|}
\hline PU & Anisotropy Index & Number of Cell/ $\left(\mathrm{mm}^{2}\right)$ & Average Cell Area $\left(\mathrm{mm}^{2}\right)$ \\
\hline 9 & $0.97 \pm 0.05$ & $21 \pm 2$ & $0.242 \pm 0.044$ \\
\hline 11 & $1.09 \pm 0.12$ & $8 \pm 2$ & $0.503 \pm 0.063$ \\
\hline 12 & $1.12 \pm 0.06$ & $109 \pm 7$ & $0.023 \pm 0.008$ \\
\hline 14 & $1.16 \pm 0.07$ & $39 \pm 4$ & $0.152 \pm 0.012$ \\
\hline
\end{tabular}

Finally, a comparison of the mechanical properties of the PUs 9-11 and the PU composites 12-14 was carried out $[37,60]$. The results are reported in Table 3.

Products 10 and 13 show a high density, of about $1000 \mathrm{~kg} / \mathrm{m}^{3}$, and a brittle behaviour. The material, during the compression test, fractured without significant plastic deformation. The maximum values of the stress-strain curves are $0.95 \mathrm{MPa}$ and $1.1 \mathrm{MPa}$ for $\mathbf{1 0}$ and 13, respectively. The compounds 9 and 12 show lower density (about $290 \mathrm{~kg} / \mathrm{m}^{3}$ ), and better compressive strength (compared to compounds $\mathbf{1 0}$ and 13), with a leathery behaviour. In the stress-strain curve, after an initial linear loading regime, the foam specimens show relatively abrupt yielding, followed by a sustained plateau region. Finally, $\mathbf{1 1}$ and $\mathbf{1 4}$ have a rubbery behaviour and a density comparable to $\mathbf{9}$ and $\mathbf{1 2}$. For this type of material, the 
breaking load has not been evaluated, as they are elastomers; in fact, they deform during the compression test and, after the load is released, they return to their initial dimensions.

Table 3. Mechanical properties of PUs 9-11 and PU composites 12-14.

\begin{tabular}{ccc}
\hline Substrates & Density $\mathbf{( k g / \mathbf { m } ^ { 3 } )}$ & Compressive Strength (MPa) \\
\hline $\mathbf{9}$ & $260 \pm 10$ & $2.03 \pm 0.04$ \\
$\mathbf{1 0}$ & $970 \pm 10$ & $0.95 \pm 0.05$ \\
$\mathbf{1 1}$ & $270 \pm 10$ & - \\
$\mathbf{1 2}$ & $290 \pm 10$ & $2.41 \pm 0.09$ \\
$\mathbf{1 3}$ & $1000 \pm 10$ & $1.10 \pm 0.06$ \\
$\mathbf{1 4}$ & $280 \pm 10$ & - \\
\hline
\end{tabular}

\section{Conclusions}

In conclusion, bio-based composite materials were successfully synthesized and characterized. The syntheses were carried out by two-step routes by using, in the second step (elongation stage), a furan-enriched polyol, derived from cellulose, as a chain extender to synthesize eco-sustainable polyurethane foams. In particular, our efforts made it possible to reduce bio-oil in an innovative manner, in an open-air reaction flask and under atmospheric pressure, to obtain a furan-enriched polyol, a privileged renewable platform molecule with a wide range of applications in the present and for the future. We used this product and we proved that is an optimal chain extender for this kind of polymer. For the second series of composites, cellulose citrate, another renewable material, was employed as a thickener for the first time, and it was added into the same reaction mixture to obtain novel composite materials with enhanced mechanical properties. In fact, from preliminary mechanical data, it seems that the use of cellulose citrate as an additive improves the mechanical performance of the materials, increasing their compressive strength. Moreover, the experimental data confirm that the hyperbranched structure of the cellulose citrate introduced into polyurethane chains increases the hydrogen bonds in the PU system (see Figure 2), causing a compression of volume and a more compact structure in the composite materials. In general, prepared bio-based polyurethane foams and their composites show good mechanical properties; therefore, we believe that our innovative method should be considered very attractive. Certainly, ulterior studies will be necessary in order to establish other properties of our materials—-such as thermal conductivity and thermal stability—for such applications as insulators.

In the future, we can consider the potential use of our products in the industrial sector, and in agrifood and agroforestry waste processing, as a source of cellulose citrate and furanenriched polyol, with strong environmental impact due to the recycling of waste material. Therefore, a wider application of this simple, efficient and eco-sustainable methodology may represent a valid alternative to other elaborate processes that are currently in use; moreover, the production of novel bio-based polyurethane foams and polyurethane composites, with their chemical and physical properties, will surely be informative for future applications in this research field.

Supplementary Materials: The following are available online at https://www.mdpi.com/article/10 .3390 / polym13162802/s1. Section S1: Reagents; Section S2: FT-IR spectra of PEG 400, isocyanates and the relative prepolymers; Section S3: FT-IR spectra of biomass derived polyol (1); Section S4: LC-MS spectrum of polyol (1); Section S5: FT-IR spectra of biomass-based polyurethanes; Section S6: Composite material processing equipment; Section S7: Photographs of bio-based polyurethanes; Section S8: Photographs of bio-based composite materials.

Author Contributions: Conceptualization: L.M. and A.D.N.; Supervision: L.M. and A.D.N.; investigation: L.M., F.O., P.C. and A.D.N.; resources: L.M. and A.D.N.; writing-original draft: L.M., F.O. and A.D.N.; writing-review and editing: L.M.; P.C. and A.D.N.; funding acquisition: L.M. and A.D.N.; methodology: F.O., V.A., A.J. and M.A.T.; formal analysis: F.O., V.A., A.J., M.A.T., A.T., C.S. 
and A.F.; data curation: F.O.; V.A., A.J., A.T., C.S. and A.F. All authors have read and agreed to the published version of the manuscript.

Funding: This research was supported by the FOREST-COMP-CUP H56C18000080005-PON "Ricerca e Innovazione 2014-2020" project. The University of Calabria and Calabria Region (PAC CALABRIA 2014-2020-Asse Prioritario 12, Azione B 10.5.12 CUP: H28D19000040006) are acknowledged for their financial support.

Institutional Review Board Statement: Not applicable.

Informed Consent Statement: Not applicable.

Data Availability Statement: Data are contained within the article.

Conflicts of Interest: The authors declare no conflict of interest.

\section{References}

1. Alonso, D.M.; Bond, J.Q.; Dumesic, J.A. Catalytic conversion of biomass to biofuels. Green Chem. 2010, 12, 1493-1513. [CrossRef]

2. Mascal, M. 5-(Chloromethyl) furfural (CMF): A platform for transforming cellulose into commercial products. ACS Sustain. Chem. Eng. 2019, 7, 5588-5601. [CrossRef]

3. Singh, H.; Sharma, A.; Bhardwaj, S.K.; Arya, S.K.; Bhardwaj, N.; Khatri, M. Recent advances in the applications of nanoagrochemicals for sustainable agricultural development. Environ. Sci. Process. Impacts 2021, 23, 213-239. [CrossRef]

4. Li, J.; Jiang, Z.; Hu, L.; Hu, C. Selective conversion of cellulose in corncob residue to levulinic acid in an aluminum tri-chloridesodiumchloride system. ChemSusChem 2014, 7, 2482-2488. [CrossRef]

5. Collins, T.J. Review of the twenty-three year evolution of the first university course in green chemistry: Teaching future leaders how to create sustainable societies. J. Clean. Prod. 2017, 140, 93-110. [CrossRef]

6. Horváth, I.T. Introduction: Sustainable chemistry. Chem. Rev. 2018, 118, 369-371. [CrossRef] [PubMed]

7. Anjali, K.; Venkatesha, N.J.; Christopher, J.; Sakthivel, A. Rhodium porphyrin molecule-based catalysts for the hydrogenation of biomass derived levulinic acid to biofuel additive c-valerolactone. New J. Chem. 2020, 44, 11064-11075. [CrossRef]

8. Qiu, X.; Hu, S. "Smart" materials based on cellulose: A review of the preparations, properties, and applications. Materials 2013, 6, 738-781. [CrossRef] [PubMed]

9. Hassan, N.S.; Jalil, A.A.; Hitam, C.N.C.; Vo, D.V.N.; Nabgan, W. Biofuels and renewable chemicals production by catalytic pyrolysis of cellulose: A review. Environ. Chem. Lett. 2020, 18, 1625-1648. [CrossRef]

10. Maiuolo, L.; Algieri, V.; Olivito, F.; Tallarida, M.A.; Costanzo, P.; Jiritano, A.; De Nino, A. Chronicle of nanocelluloses (NCs) for catalytic applications: Key advances. Catalysts 2021, 11, 96. [CrossRef]

11. Baghaei, B.; Skrifvars, M. All-cellulose composites: A Review of recent studies on structure, properties and applications. Molecules 2020, 25, 2836. [CrossRef]

12. Shen, D.; Xiao, R.; Gu, S.; Luo, K. The pyrolytic behavior of cellulose in lignocellulosic biomass: A review. RSC Adv. 2011, 1, 1641-1660. [CrossRef]

13. Kan, T.; Strezov, V.; Evans, T.J. Lignocellulosic biomass pyrolysis: A review of product properties and effects of pyrolysis parameters. Renew. Sustain. Energy Rev. 2016, 57, 1126-1140. [CrossRef]

14. Yang, G.; Yang, J.; Huang, D.; Zhou, W.; Yang, L.; Lv, P.; Yi, W.; Sun, Y.; Yan, B. BTX production from rice husk by fast catalytic pyrolysis over a Ga-modified ZSM-5/SBA-15 catalyst. New J. Chem. 2021, 45, 3809-3816. [CrossRef]

15. Chinnappan, A.; Baskar, C.; Kim, H. Biomass into chemicals: Green chemical conversion of carbohydrates into 5hydroxymethylfurfural in ionic liquids. RSC Adv. 2016, 6, 63991-64002. [CrossRef]

16. Pang, J.; Zheng, M.; Li, X.; Sebastian, J.; Jiang, Y.; Zhao, Y.; Wang, A.; Zhang, T. Unlock the compact structure of lignocel-lulosic biomass by mild ball milling for ethylene glycol production. ACS Sustain. Chem. Eng. 2019, 7, 679-687. [CrossRef]

17. Gaudino, E.C.; Cravotto, G.; Manzoli, M.; Tabasso, S. From waste biomass to chemicals and energy via microwave-assisted processes. Green Chem. 2019, 21, 1202-1235. [CrossRef]

18. Li, Z.; Su, K.; Ren, J.; Yang, D.; Cheng, B.; Kim, C.K.; Yao, X. Direct catalytic conversion of glucose and cellulose. Green Chem. 2018, 20, 863-872. [CrossRef]

19. Palkovits, R.; Tajvidi, K.; Procelewska, J.; Rinaldia, R.; Ruppert, A. Hydrogenolysis of cellulose combining mineral acids and hydrogenationcatalysts. Green Chem. 2010, 12, 972-978. [CrossRef]

20. Chang, J.K.-W.; Duret, X.; Berberi, V.; Zahedi-Niaki, H.; Lavoie, J.-M. Two-step thermochemical cellulose hydrolysis with partial neutralization for glucose production. Front. Chem. 2018, 6, 117-127. [CrossRef]

21. Calandra, P.; Szerb, E.; Lombardo, D.; Algieri, V.; De Nino, A.; Maiuolo, L. A Presentation of ionic liquids as lubricants: Some critical comments. Appl. Sci. 2021, 11, 5677. [CrossRef]

22. Maiuolo, L.; Algieri, V.; Olivito, F.; De Nino, A. Recent developments on 1,3-dipolar cycloaddition reactions by catalysis in green solvents. Catalysts 2020, 10, 65. [CrossRef] 
23. Kuroda, K.; Miyamura, K.; Satria, H.; Takada, K.; Ninomiya, K.; Takahashi, K. Hydrolysis of cellulose using an acidic and hydrophobic ionic liquid and subsequent separation of glucose aqueous solution from the ionic liquid and 5-(Hydroxymethyl) furfural. ACS Sustain. Chem. Eng. 2016, 4, 3352-3356. [CrossRef]

24. Chen, T.; Xiong, C.; Tao, Y. Enhanced hydrolysis of cellulose in ionic liquid using mesoporous ZSM-5. Molecules 2018, 23, 529. [CrossRef]

25. Loow, Y.-L.; New, E.K.; Yang, G.H.; Ang, L.Y.; Foo, L.Y.W.; Wu, T.Y. Potential use of deep eutectic solvents to facilitate lignocellulosic biomass utilization and conversion. Cellulose 2017, 24, 3591-3618. [CrossRef]

26. Liu, F.; Xue, Z.; Zhao, X.; Mou, H.; He, J.; Mu, T. Catalytic deep eutectic solvents for highly efficient conversion of cellulose to gluconic acid with gluconic acid self-precipitation separation. Chem. Commun. 2018, 54, 6140-6143. [CrossRef] [PubMed]

27. Liveri, V.T.; Lombardo, D.; Pochylski, M.; Calandra, P. Molecular association of small amphiphiles: Origin of ionic liquid properties in dibutyl phosphate/propylamine binary mixtures. J. Mol. Liq. 2018, 263, 274-281. [CrossRef]

28. Calandra, P.; Mandanici, A.; Liveri, V.T. Self-assembly in surfactant-based mixtures driven by acid-base reactions: Bis(2-ethylhexyl) phosphoric acid-n-octylamine systems. RSC Adv. 2013, 3, 5148-5155. [CrossRef]

29. Barakat, A.; Mayer-Laigle, C.; Solhy, A.; Arancon, R.A.D.; De Vries, H.; Luque, R. Mechanical pretreatments of lignocellulosic biomass: Towards facile and environmentally sound technologies for biofuels production. RSC Adv. 2014, 4, 48109-48127. [CrossRef]

30. Yang, C.; Yuan, X.; Wang, X.; Wu, K.; Liu, Y.; Liu, C.; Lu, H.; Liang, B. Ball milling promoted direct liquefaction of lignocellulosic biomass in supercritical ethanol. Front. Chem. Sci. Eng. 2019, 14, 605-613. [CrossRef]

31. Wang, Q.; Sun, J.; Yao, Q.; Ji, C.; Liu, J.; Zhu, Q. 3D printing with cellulose materials. Cellulose 2018, 25, 4275-4301. [CrossRef]

32. Khan, A.; Jagdale, P.; Rovere, M.; Nogués, M.; Rosso, C.; Tagliaferro, A. Carbon from waste source: An eco-friendly way for strengthening polymer composites. Compos. Part B Eng. 2018, 132, 87-96. [CrossRef]

33. Golling, F.E.; Pires, R.; Hecking, A.; Weikard, J.; Richter, F.; Danielmeier, K.; Dijkstra, D. Polyurethanes for coatings and ad-hesives-chemistry and applications. Polym. Int. 2019, 68, 848-855. [CrossRef]

34. De Avila Delucis, R.; Magalhães, W.L.E.; Petzhold, C.L.; Amico, S.C. Forest-based resources as fillers in biobased polyurethane foams. J. Appl. Polym. Sci. 2018, 135, 45684. [CrossRef]

35. Zhang, H.; Fang, W.-Z.; Li, Y.-M.; Tao, W.-Q. Experimental study of the thermal conductivity of polyurethane foams. Appl. Therm. Eng. 2017, 115, 528-538. [CrossRef]

36. Gharib, J.; Pang, S.; Holland, D. Synthesis and characterisation of polyurethane made from pyrolysis bio-oil of pine wood. Eur. Polym. J. 2020, 133, 109725. [CrossRef]

37. Akindoyo, J.O.; Beg, M.D.H.; Ghazali, S.; Islam, M.R.; Jeyaratnam, N.; Yuvaraj, A.R. Polyurethane types, synthesis and applications-A review. RSC Adv. 2016, 6, 114453-114482. [CrossRef]

38. Rokickia, G.; Parzuchowskia, P.G.; Mazurek, M. Non-isocyanate polyurethanes: Synthesis, properties, and applications. Polym. Adv. Technol. 2015, 26, 707-761. [CrossRef]

39. Calvo-Correas, T.; Martin, M.D.; Retegi, A.; Gabilondo, N.; Corcuera, M.A.; Eceiza, A. Synthesis and Characterization of Polyurethanes with High Renewable Carbon Content and Tailored Properties. ACS Sustain. Chem. Eng. 2016, 4, 5684-5692. [CrossRef]

40. Cao, J.; Chen, N.; Chen, Y.; Luo, X. Synthesis of a novel biodegradable polyurethane with phosphatidylcholines. Int. J. Mol. Sci. 2010, 11, 1870-1877. [CrossRef] [PubMed]

41. Aberasturi, O.G.J.; Gómez, J.R.O. New approaches to producing polyols from biomass. J. Chem. Technol. Biotechnol. 2017, 92, 705-711. [CrossRef]

42. Arnaud, S.P.; Wu, L.; Chang, M.-A.W.; Comerford, J.W.; Farmer, T.J.; Schmid, M.; Chang, F.; Li, Z.; Mascal, M. New bio-based monomers: Tuneable polyester properties using branched diols from biomass. Faraday Discuss. 2017, 202, 61-77. [CrossRef] [PubMed]

43. Choi, S.M.; Lee, M.W.; Shin, E.J. One-pot processing of regenerated cellulose nanoparticles/waterborne polyurethane nanocomposite for eco-friendly polyurethane matrix. Polymers 2019, 11, 356. [CrossRef] [PubMed]

44. Romeo, I.; Olivito, F.; Tursi, A.; Algieri, V.; Beneduci, A.; Chidichimo, G.; Maiuolo, L.; Sicilia, E.; De Nino, A. Totally green cellulose conversion into bio-oil and cellulose citrate using molten citric acid in an open system: Synthesis, characterization and computational investigation of reaction mechanisms. RSC Adv. 2020, 10, 34738-34751. [CrossRef]

45. Maiuolo, L.; Olivito, F.; Ponte, F.; Algieri, V.; Tallarida, M.A.; Tursi, A.; Chidichimo, G.; Sicilia, E.; De Nino, A. A novel catalytic two-step process for the preparation of rigid polyurethane foams: Synthesis, mechanism and computational studies. React. Chem. Eng. 2021, 6, 1238-1245. [CrossRef]

46. Yuan, H.; Kusema, B.T.; Yan, Z.; Streiff, S.; Shi, F. Highly selective synthesis of 2,5-bis(aminomethyl)furan via catalytic ami-nation of 5-(hydroxymethyl)furfural with $\mathrm{NH}_{3}$ over a bifunctional catalyst. $R S C$ Adv. 2019, 9, 38877-38881. [CrossRef]

47. Zhao, W.; Wu, W.; Li, H.; Fang, C.; Yang, T.; Wang, Z.; He, C.; Yang, S. Quantitative synthesis of 2,5-bis(hydroxymethyl)furan from biomass-derived 5-hydroxymethylfurfural and sugars over reusable solid catalysts at low temperatures. Fuel 2018, 217, 365-369. [CrossRef]

48. Nguyen, H.; Wang, Y.; Moglia, D.; Fu, J.; Zheng, W.; Orazov, M.; Vlachos, D.G. Production of renewable oleo-furan surfactants by cross-ketonization of biomass-derived furoic acid and fatty acids. Catal. Sci. Technol. 2021, 11, 2762-2769. [CrossRef] 
49. Amran, U.A.; Zakaria, S.; Chia, C.H.; Roslan, R.; Jaafar, S.N.S.; Salleh, K.M. Polyols and rigid polyurethane foams derived from liquefied lignocellulosic and cellulosic biomass. Cellulose 2019, 26, 3231-3246. [CrossRef]

50. Zoghlami, A.; Paës, G. Lignocellulosic biomass: Understanding recalcitrance and predicting hydrolysis. Front. Chem. 2019, 7, 874. [CrossRef] [PubMed]

51. Zhou, L.; Gao, D.; Yang, J.; Yang, X.; Su, Y.; Lu, T. Conversion of recalcitrant cellulose to alkyl levulinates and levulinic acid via oxidation pretreatment combined with alcoholysis over $\mathrm{Al}_{2}\left(\mathrm{SO}_{4}\right)_{3}$. Cellulose 2019, 27, 1451-1463. [CrossRef]

52. Kanth, J.V.B.; Periasamy, M. Selective reduction of carboxylic acids into alcohols using sodium borohydride and iodine. J. Org. Chem. 1991, 56, 5964-5965. [CrossRef]

53. Sardon, H.; Pascual, A.; Mecerreyes, D.; Taton, D.; Cramail, H.; Hedrick, J.L. Synthesis of polyurethanes using organocatalysis: A perspective. Macromolecules 2015, 48, 3153-3165. [CrossRef]

54. Motokucho, S.; Nakayama, Y.; Morikawa, H.; Nakatani, H. Environment-friendly chemical recycling of aliphatic polyure-thanes by hydrolysis in a $\mathrm{CO}_{2}$-water system. J. Appl. Polym. Sci. 2018, 135, 45897-45903. [CrossRef]

55. Głowińska, E.; Wolak, W.; Datta, J. Eco-friendly route for thermoplastic polyurethane elastomers with bio-based hard seg-ments composed of bio-glycol and mixtures of aromatic-aliphatic and aliphatic-aliphatic diisocyanate. J. Polym. Environ. 2021, 29, 2140-2149. [CrossRef] [PubMed]

56. Calandra, P.; Caponetti, E.; Chillura Martino, D.; D'Angelo, P.; Minore, A.; Turco Liveri, V. FT-IR and dielectric study of water/AOT liquid crystals. J. Mol. Struct. 2000, 522, 165-178. [CrossRef]

57. Kowalczuk, D.; Pitucha, M. Application of FTIR method for the assessment of immobilization of active substances in the matrix of biomedical materials. Materials 2019, 12, 2972. [CrossRef]

58. Shen, X.; Dai, J.; Liu, Y.; Liu, X.; Zhu, J. Synthesis of high performance polybenzoxazine networks from bio-based furfurylamine: Furan vs benzene ring. Polymers 2017, 122, 258-269. [CrossRef]

59. Nie, B.; Stutzman, J.; Xie, A. A vibrational spectral maker for probing the hydrogen-bonding status of protonated asp and glu residues. Biophys. J. 2005, 88, 2833-2847. [CrossRef] [PubMed]

60. Ciecierska, E.; Jurczyk-Kowalska, M.; Bazarnik, P.; Gloc, M.; Kulesza, M.; Kowalski, M.; Krauze, S.; Lewandowska, M. Flammability, mechanical properties and structure of rigid polyurethane foams with different types of carbon reinforcing materials. Compos. Struct. 2016, 140, 67-76. [CrossRef]

61. Calandra, P.; Mandanici, A.; Liveri, V.T.; Pochylski, M.; Aliotta, F. Emerging dynamics in surfactant-based liquid mixtures: Octanoic acid/bis(2-ethylhexyl) amine systems. J. Chem. Phys. 2012, 136, 064515. [CrossRef]

62. Calandra, P. On the physico-chemical basis of self-nanosegregation giving magnetically-induced birefringence in dibutyl phosphate/bis(2-ethylhexyl) amine systems. J. Mol. Liq. 2020, 310, 113186. [CrossRef]

63. Uram, K.; Leszczyńska, M.; Prociak, A.; Czajka, A.; Gloc, M.; Leszczyński, M.; Michałowski, S.; Ryszkowska, J. Polyurethane composite foams synthesized using bio-polyols and cellulose filler. Materials 2021, 14, 3474. [CrossRef] [PubMed]

64. Septevani, A.A.; Evans, D.A.C.; Martin, D.J.; Annamalai, P.K. Hybrid polyether-palm oil polyester polyol based rigid polyurethane foam reinforced with cellulose nanocrystal. Ind. Crops Prod. 2018, 112, 378-388. [CrossRef]

65. Zhou, X.; Sain, M.M.; Oksman, K. Semi-rigid biopolyurethane foams based on palm-oil polyol and reinforced with cellulose nanocrystals. Compos. Part A Appl. Sci. Manuf. 2016, 83, 56-62. [CrossRef] 